\title{
The Photocatalytic Decomposition of Different Organic Dyes under UV Irradiation with and without $\mathrm{H}_{2} \mathrm{O}_{2}$ on Fe-ACF/TiO ${ }_{2}$ Photocatalysts
}

\author{
Kan Zhang and Won-Chun $\mathrm{Oh}^{\dagger}$ \\ Department of Advanced Materials \& Science Engineering, Hanseo University, Chungnam 356-706, Korea \\ (Received July 7, 2009; Revised August 5, 2009; Accepted August 6, 2009)
}

\begin{abstract}
The Fe-ACF/TiO ${ }_{2}$ composites were prepared by a sol-gel method and were characterized by nitrogen adsorption, Scanning Electron Microscopy (SEM), X-ray Diffraction (XRD), and Energy Dispersive X-ray (EDX). The Fe-ACF/TiO ${ }_{2}$ composites were developed for the decomposition of organic dyes by using a UV lamp. The decomposition effect was investigated under various conditions, such as three selected non-biodegradable organic dyes like Methylene Blue (MB), Methyl Orange (MO), Rhodamine B (Rh.B), and in the presence of $\mathrm{Fe}$ and hydrogen peroxide $\left(\mathrm{H}_{2} \mathrm{O}_{2}\right)$. The photocatalytic activity was derived from possible combination effects, such as (1) adsorption of ACF, (2) generation of electron/hole by $\mathrm{TiO}_{2}$, (3) photo-Fenton reaction of $\mathrm{Fe}$, and (4) oxidation of $\mathrm{Fe}^{2+}$ to $\mathrm{Fe}^{3+}$ by $\mathrm{H}_{2} \mathrm{O}_{2}$.
\end{abstract}

Key words : $\mathrm{Fe}-\mathrm{ACF} / \mathrm{TiO}_{2}$ composites, Photocatalytic, $\mathrm{H}_{2} \mathrm{O}_{2}$, Photo-Fenton, Organic dyes

\section{Introduction}

$\mathrm{T}$ he industrial and textile wastewaters is a considerable source of non-aesthetic pollution in the environment and can create dangerous byproducts through oxidation, hydrolysis, or other chemical reactions that take place in the wastewater phase. ${ }^{1-4)}$ Therefore, removing such contaminants is a major focus in reducing environmental pollution. In recent years, the photocatalytic decomposition of organic pollutants in water by suspending $\mathrm{TiO}_{2}$ as a catalyst has been widely studied. ${ }^{5,6)}$ When $\mathrm{TiO}_{2}$ absorbs a photon of energy that is equal to or greater than its band gap width, an electron may travel from the valence band to the conduction band $\left(\mathrm{e}_{\mathrm{cb}}{ }^{-}\right)$where a photohole will be generated, as well as electrons in the valence band $\left(\mathrm{h}_{\mathrm{vb}}{ }^{+}\right)$. In particular, $\mathrm{h}_{\mathrm{vb}}{ }^{+}$may react with surface-bound $\mathrm{H}_{2} \mathrm{O}$ or $\mathrm{OH}^{-}$to produce the hydroxyl radical $\left(\mathrm{OH}^{\bullet}\right)$ and $\mathrm{e}_{\mathrm{cb}}{ }^{-}$is picked up by oxygen to generate superoxide radical anion $\left(\mathrm{O}_{2}{ }^{-}\right)$. It has been suggested that the hydroxyl radicals $\left(\mathrm{OH}^{\bullet}\right)$ and superoxide radical anions $\left(\mathrm{O}_{2}{ }^{--}\right)$have a powerful capability in removing organic functional groups from the photocatalytic decomposition processes. Moreover, the decomposition effect for different organic dyes molecules is different.

Since the suspended $\mathrm{TiO}_{2}$ powders present some drawbacks, the powders not being able to be easily precipitated and recovered from the water. And, these drawbacks can be harmful to the powders' regeneration and reuse. Therefore, many studies have been devoted to immobilizing $\mathrm{TiO}_{2}$ on

${ }^{\dagger}$ Corresponding author: Won-Chun $\mathrm{Oh}$

E-mail : wc_oh@hanseo.ac.kr

Tel : +82-41-660-1337 Fax : +82-41-688-3352 different substrate materials. ${ }^{7,8)}$ Activated Carbon Fiber (ACF), which has good adsorption and a uniform pore structure, has been widely used as a catalyst support for different purposes. ${ }^{9-13)}$ In addition, ACF can attract more water molecules and/or organic binder on the $\mathrm{TiO}_{2}$ surface. Therefore, ACF is an ideal substrate for $\mathrm{TiO}_{2}$ immobilization.

Moreover, for $\mathrm{TiO}_{2}$ itself, there are some limitations due to the capability of electron/hole pairs to recombine within nanoseconds, ${ }^{14)}$ which can only happen with a light illumination of a suitable wavelength $\left(\lambda<390 \mathrm{~nm}\right.$ or $\mathrm{E}_{\mathrm{bg}}=$ $3.2 \mathrm{eV})^{15-19)}$ and with low photon utilization efficiency. In order to surmount these demerits, incorporating transition metal ions like $\mathrm{Cr},{ }^{20)} \mathrm{Mn},{ }^{21)} \mathrm{Co},{ }^{22)} \mathrm{Cu},{ }^{23)} \mathrm{Zr},{ }^{2425)} \mathrm{Fe},{ }^{26-29)}$ into the $\mathrm{TiO}_{2}$ lattice host could remarkably increase photocatalytic activity. This is especially true when Fe could act as both hole and electron traps that can enhance the photocatalytic activity of $\mathrm{TiO}_{2}{ }^{30}$ ) and produce photo-Fenton reactions by reducing $\mathrm{Fe}^{3+}$ to $\mathrm{Fe}^{2+}$. From the above points, combining $\mathrm{ACF}$ and $\mathrm{TiO}_{2}$ with $\mathrm{Fe}$ was considered reliable behavior for increasing photocatalytic activity.

According to previous studies, ${ }^{31)}$ it is well-known that the photo-Fenton process is governed by the amount and ratio of $\mathrm{Fe}^{2+} / \mathrm{Fe}^{3+}$, because the yield of photo-Fenton reactions is lower when there is an excess of $\mathrm{Fe}^{2+}$ ions. Many authors used oxygen gas to oxidate $\mathrm{Fe}^{2}$ to $\mathrm{Fe}^{3+}$ as Fenton's reagent. ${ }^{32-34)}$ $\mathrm{O}_{2}$ is a more environmentally-friendly oxidant, but it still offers low conversion. Some homogeneous and heterogeneous catalytic systems that consisted of Fenton's reagent have been investigated for oxidating $\mathrm{Fe}^{2+}$ to $\mathrm{Fe}^{3+}$ by using $\mathrm{H}_{2} \mathrm{O}_{2}{ }^{35-37)}$ The use of $\mathrm{H}_{2} \mathrm{O}_{2}$ oxidation catalysts with Fenton catalysts proves that they can form more $\mathrm{OH}$ radicals and can be reused in the following processes: 
Table 1. The Properties of ACFs

\begin{tabular}{ll}
\hline \multicolumn{1}{c}{ Physical properties } & \multicolumn{1}{c}{ Units } \\
\hline Density & $1.23 \sim 1.91 \mathrm{~g} / \mathrm{mL}$ \\
Electrical Resistivity & $5.2 \times 10^{-3} \sim 6.8 \times 10^{-3} \Omega \cdot \mathrm{cm}$ \\
Diameter & $12 \sim 15 \mu$ \\
Tensile Strength & $4 \sim 6 \times 10^{8} \mathrm{~Pa}$ \\
Tensile Modulus & $3 \times 10^{10} \sim 4 \times 10^{10} \mathrm{~Pa}$ \\
Elemental carbon & $\geq 95 \mathrm{wt} \%$ \\
\hline
\end{tabular}

$$
\mathrm{Fe}^{2+}+\mathrm{H}_{2} \mathrm{O}_{2} \rightarrow \mathrm{Fe}^{3+}+\mathrm{OH}^{\bullet}+\mathrm{HO}^{-}
$$

$\mathrm{Fe}^{3+}+\mathrm{HO}^{-}+\mathrm{h}^{+} \rightarrow \mathrm{Fe}^{2+}+\mathrm{OH}^{\bullet}$

The reaction (1) and (2) showed the powerful recuperation of $\mathrm{Fe}^{3+}$ and the reuse of the catalyst, which proves that the yield of photo-Fenton reactions is higher when there is an excess of $\mathrm{Fe}^{2+}$ ions.

In this paper, $\mathrm{Fe}-\mathrm{ACF} / \mathrm{TiO}_{2}$ composites were synthesized and the decomposition of different dyes, like MB, Rh.B, and MO dyes were studied under UV irradiation both with and without $\mathrm{H}_{2} \mathrm{O}_{2}$. The synthesized catalyst was characterized as being BET, SEM, XRD and EDX.

\section{Experimental Procedure}

\subsection{Materials}

Activated Carbon Fiber (ACF) was purchased from EAST ASIS Carbon Fibers Co., Ltd, (Anshan, China). Their properties are shown in Table 1 . Hydrogen peroxide $\left(\mathrm{H}_{2} \mathrm{O}_{2}, 35 \%\right)$ was purchased from Daejung Chemicals \& Metals Co., Ltd, (Korea). Titanium (IV) oxysulfate hydrate $\left(\mathrm{TiOSO}_{4} \cdot \mathrm{xH}_{2} \mathrm{O}\right.$ (TOS) 99.99\%) was used as a titanium source, which was purchased from Sigma-Aldrich, (Germany), while $\mathrm{Fe}\left(\mathrm{NO}_{3}\right)_{3} \cdot 9 \mathrm{H}_{2} \mathrm{O}$ (99+\%) as the ferric source was purchased from Duksan Pure Chemical Co., Ltd, (Korea). The MB (99.99+\%) was used as an analytical grade, which was purchased from Duksan Pure Chemical Co., Ltd, (Korea). The Rh.B (99.99+\%) was purchased from Samchun Pure Chemical Co., Ltd, (Korea). The MO (99.99+\%) was purchased from Daejung Chemicals \& metals Co., Ltd, (Korea).

\subsection{Preparation of samples}

For this experimental process, $10 \mathrm{~g} \mathrm{ACF}$ power was first added into to a $50 \mathrm{ml} 0.25 \mathrm{M} \mathrm{Fe}\left(\mathrm{NO}_{3}\right)_{3} \cdot 9 \mathrm{H}_{2} \mathrm{O}$ solution and the mixtures were stirred for $24 \mathrm{~h}$ by a non-magnetic stirrer at room temperature. After being heated at $773 \mathrm{~K}$, the Fe-ACF was obtained. The Fe-ACF was put into the mixture of TOS and ethanol. Then, the mixed solution was stirred for $5 \mathrm{~h}$ in an air atmosphere. After the stirring solution was transformed to a gel state, these gels were heat treated at $923 \mathrm{~K}$ for $1 \mathrm{~h}$. Then, the Fe-treated $\mathrm{ACF} / \mathrm{TiO}_{2}$ composites were also obtained. The nomenclatures of the prepared samples are listed in Table 2. At the same time, an original sample of ACF/ $\mathrm{TiO}_{2}$ was cited from the former experiment ${ }^{38)}$ and compared with that of the $\mathrm{Fe}-\mathrm{ACF} / \mathrm{TiO}_{2}$ composites that were obtained.
Table 2. Nomenclatures of $\mathrm{ACF} / \mathrm{TiO}_{2}$ and $\mathrm{Fe}-\mathrm{ACF} / \mathrm{TiO}_{2}$ Composites

\begin{tabular}{cc}
\hline Sample & Nomenclatures \\
\hline $\mathrm{ACF}+\mathrm{Titanium}$ iso propoxide & AT \\
$\mathrm{ACF}+\mathrm{Fe}\left(\mathrm{NO}_{3}\right)_{3}(0.25 \mathrm{M})+\mathrm{TOS}$ & FAT \\
\hline
\end{tabular}

Table 3. Structural Representation of Some Selected Organic Dyes

$\mathrm{MB} \lambda \max =660 \mathrm{~nm}$

2.3. Characteristics and investigations of the samples The BET surface area by $\mathrm{N}_{2}$ adsorption method was measured at $77 \mathrm{~K}$ by a BET analyzer (Monosorb, Quantachrome Instruments Ltd., USA). The XRD (XD-D1 Shimadz Ltd., Japan) result was used to identify the crystallinity from the $\mathrm{Cu} \mathrm{K} \alpha$ radiation. SEM was used to observe the surface state and structure of $\mathrm{Fe}-\mathrm{ACF} / \mathrm{TiO}_{2}$ composites by SEM (JSM5200 JOEL Ltd., Japan). EDX (JSM-5200 JOEL Ltd., Japan) spectra were also obtained for determining the elemental information of the $\mathrm{ACF} / \mathrm{TiO}_{2}$ and $\mathrm{Fe}-\mathrm{ACF} / \mathrm{TiO}_{2}$ composites. UV-vis absorption parameters for the $\mathrm{MB}$ solution were decomposed by $\mathrm{ACF} / \mathrm{TiO}_{2}$ and $\mathrm{Fe}-\mathrm{ACF} / \mathrm{TiO}{ }_{2}$ composites under UV lamp irradiation (both with $\mathrm{H}_{2} \mathrm{O}_{2}$ and without $\mathrm{H}_{2} \mathrm{O}_{2}$ ) and they were recorded by using a (Spectronic 21 Bausch \& Lomb Ltd., USA) spectrophotometer.

\subsection{Photocatalytic activity of $\mathrm{Fe}-\mathrm{ACF}_{\mathbf{T i O}}$}

The photochemical data that were presented as behaviors of the organic dyes (MB, Rh.B and MO) were decomposed by $\mathrm{ACF} / \mathrm{TiO}_{2}$ and $\mathrm{Fe}-\mathrm{ACF} / \mathrm{TiO}_{2}$ composites in a $100 \mathrm{~mL}$ glass container, and in an irradiation system by UV, both with $\mathrm{H}_{2} \mathrm{O}_{2}$ and without $\mathrm{H}_{2} \mathrm{O}_{2}$, respectively. The sample powder of $0.03 \mathrm{~g}$ was suspended in the $50 \mathrm{ml}$ of organic dye (MB, Rh.B and MO) solution with a concentration of $1.0 \times 10^{-5} \mathrm{M}$. Then, the mixed solution was emplaced in the dark for at least $2 \mathrm{~h}$ in order to establish an adsorption-desorption equilibrium, which is hereafter known as the initial concentration $\left(c_{0}\right)$ after dark adsorption. Then, the experiments were carried out under two conditions: 1) UV only and 2) under UV with an addition of $1.5 \times 10^{-3} \mathrm{~mol} \mathrm{H}_{2} \mathrm{O}_{2}$ to the organic dye solution (ex, UV and $\mathrm{UV}+\mathrm{H}_{2} \mathrm{O}_{2}$, respectively). The solution was then withdrawn regularly from the reactor by an order of $30 \mathrm{~min}$, $60 \mathrm{~min}, 90 \mathrm{~min}$, and $120 \mathrm{~min}$. Afterwards, $10 \mathrm{~mL}$ of solution 
Table 4. Specific BET Surface Areas of Pristine ACF, ACF/ $\mathrm{TiO}_{2}$ and $\mathrm{Fe}-\mathrm{ACF} / \mathrm{TiO}_{2}$ Composite Samples.

\begin{tabular}{cc}
\hline Sample & $\mathrm{S}_{\mathrm{BET}}\left(\mathrm{m}^{2} / \mathrm{g}\right)$ \\
\hline Pristine ACF & 1842 \\
AT & 1268 \\
FAT & 745 \\
\hline
\end{tabular}

Table 5. EDX Elemental Microanalysis (wt\%) of $\mathrm{ACF} / \mathrm{TiO}_{2}$ and $\mathrm{Fe}-\mathrm{ACF} / \mathrm{TiO}_{2}$ Composites

\begin{tabular}{ccccc}
\hline \multirow{2}{*}{ Samples } & \multicolumn{4}{c}{ Elements (wt\%) } \\
\cline { 2 - 5 } & $\mathrm{C}$ & $\mathrm{O}$ & $\mathrm{Ti}$ & $\mathrm{Fe}$ \\
\hline AT & 65.5 & 15.4 & 18.9 & 0 \\
FAT & 67.14 & 17.63 & 6.52 & 5.18 \\
\hline
\end{tabular}

was taken out and immediately centrifuged in order to separate any suspended solid. The clean transparent solution was immediately analyzed by using a UV-vis spectrophotometer in order to decrease the continual oxidation of $\mathrm{H}_{2} \mathrm{O}_{2}$ for organic compounds residue. The extent of dye decomposition was estimated by a spectrophometer at the absorption maximum $\left(\lambda_{\max }\right)$ of the concerned dye. The molectular structures of the dyes are shown in Table 3.

\section{Results and Discussion}

\subsection{The surface characteristics}

The value of the BET surface area of pristine ACF, ACF/ $\mathrm{TiO}_{2}$ and $\mathrm{Fe}-\mathrm{ACF} / \mathrm{TiO}{ }_{2}$ samples are shown in Table 4. According to the results of Table 4, the BET surface area of the as-received $\mathrm{ACF}$ is $1842 \mathrm{~m}^{2} / \mathrm{g}$, while the BET surface area of the $\mathrm{ACF} / \mathrm{TiO}_{2}$ and $\mathrm{Fe}-\mathrm{ACF} / \mathrm{TiO} \mathrm{O}_{2}$ composites decreased to $1268 \mathrm{~m}^{2} / \mathrm{g}$ and $745 \mathrm{~m}^{2} / \mathrm{g}$. It is evident that there was a large change of the micropore size distribution for the $\mathrm{ACF} /$ $\mathrm{TiO}_{2}$ and $\mathrm{Fe}-\mathrm{ACF} / \mathrm{TiO}{ }_{2}$ composites, compared with that of the corresponding ACF. This may have been due to the partial blocking of micropores that were formed by $\mathrm{TiO}_{2}$ on the ACF surface from the heat treatment. This was especially true for the $\mathrm{Fe}-\mathrm{ACF} / \mathrm{TiO}_{2}$ composites, where the variation of surface parameters was probably caused by the $\mathrm{TiO}_{2}$ and $\mathrm{Fe}$ compounds. The similar phenomena were also observed inprevious studies. ${ }^{39,40)}$

The SEM micrographs of $\mathrm{ACF} / \mathrm{TiO}_{2}$ and $\mathrm{Fe}-\mathrm{ACF} / \mathrm{TiO}{ }_{2}$ composites are shown in Fig. 1. It can be observed in Fig. 1 (a) and (b) that the $\mathrm{TiO}_{2}$ particles were immobilized on the surface of ACF. Some adjacent fibers were connected to each other by the $\mathrm{TiO}_{2}$ particles that were deposited. Fig. 1(c) and (d) show that the $\mathrm{TiO}_{2}$ particles were deposited on the ACF as small clusters. Although the $\mathrm{TiO}_{2}$ particles were deposited on fibers at such a large scale, the Fe-ACF/TiO still retained the same spatial distribution of non-treated $\mathrm{ACF} / \mathrm{TiO}_{2}$. Therefore, adequate UV irradiation was not able to penetrate into the connect-form photocatalyst up to a certain depth in order to form a three dimensional environment for photocatalytic reactions. The rough surface of the $\mathrm{TiO}_{2}$ layer may have contributed in the increase of the

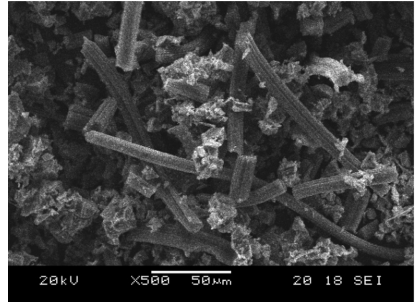

(a)

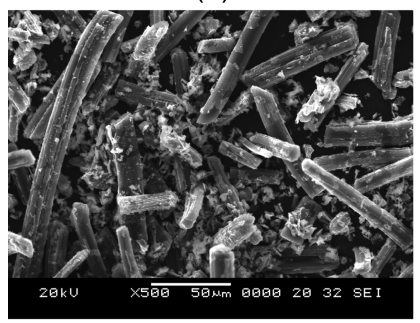

(c)

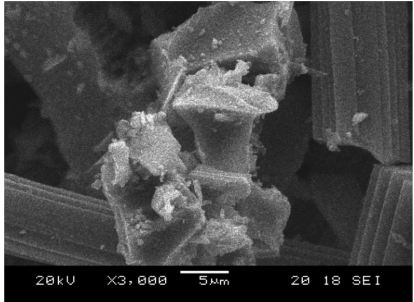

(b)

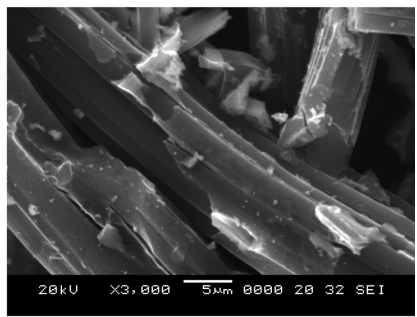

(d)
Fig. 1. SEM images of non-treated $\mathrm{ACF} / \mathrm{TiO}_{2}$ and $\mathrm{Fe}-\mathrm{ACF} /$ $\mathrm{TiO}_{2}$ composites: AT: (a) $\times 500$, (b) $\times 3000$; FAT: (c) $\times 500$, (d) $\times 3000$.

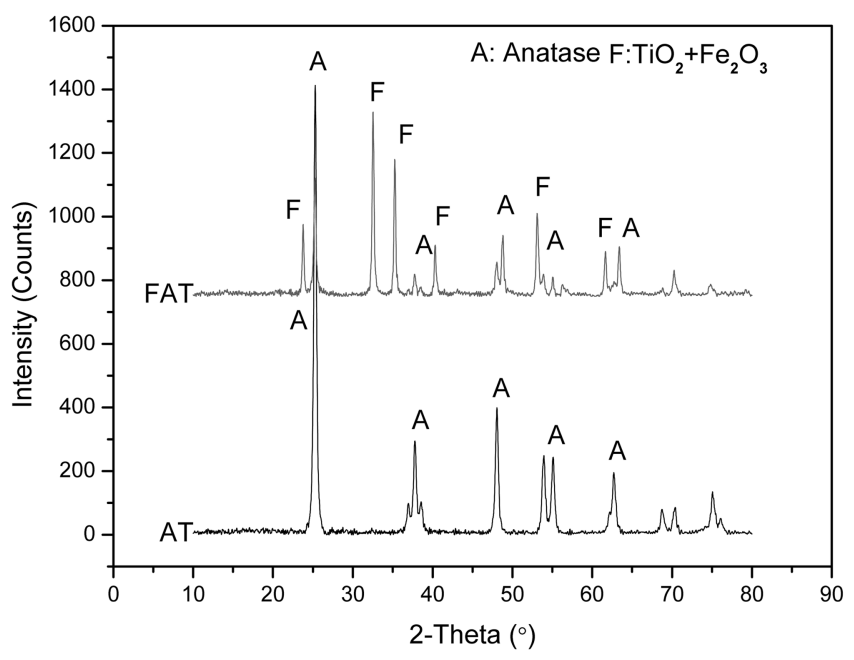

Fig. 2. XRD patterns of the powdered $\mathrm{ACF} / \mathrm{TiO}_{2}$ and $\mathrm{Fe}-\mathrm{ACF} /$ $\mathrm{TiO}_{2}$ composites.

surface area of loaded $\mathrm{TiO}_{2}$, which may have offered a greater chance of substrate adsorption onto the $\mathrm{TiO}_{2}$ surface. In addition, these small clusters of $\mathrm{TiO}_{2}$ crystals were spread over the ACF surface in an irregular shape, where the interstices among the crystalline particles provided an ideal path for the transport and adsorption of organic molecules.

\subsection{The composition of non-treated $\mathrm{ACF} / \mathrm{TiO}{ }_{2}$ and} $\mathrm{Fe}-\mathrm{ACF} / \mathrm{TiO}_{2}$

The XRD spectra of $\mathrm{ACF} / \mathrm{TiO}_{2}$ and $\mathrm{Fe}-\mathrm{ACF} / \mathrm{TiO}{ }_{2}$ composites are shown in Fig. 2. The XRD patterns of ACF/ $\mathrm{TiO}_{2}$ and $\mathrm{Fe}-\mathrm{ACF} / \mathrm{TiO}_{2}$ photocatalysts show that all of the photocatalysts have developed unique anatase-type $\mathrm{TiO}_{2}$, where the peaks of all the samples at $25.4^{\circ}, 38.2^{\circ}, 47.9^{\circ}$, $54.8^{\circ}$ and $62.6^{\circ}$ are related to the diffractions of the (101), 


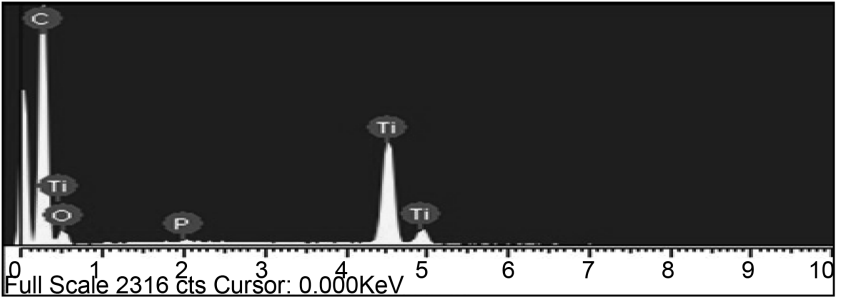

(a)

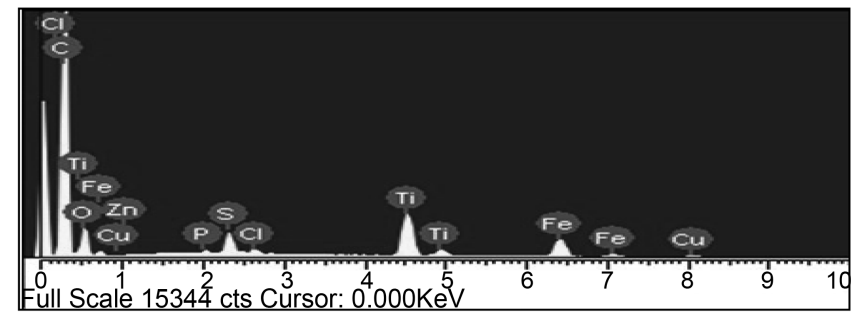

(b)

Fig. 3. EDX elemental microanalysis of $\mathrm{ACF}_{\mathrm{TiO}}$ and $\mathrm{Fe}$ ACF/TiO ${ }_{2}$ composites: (a) AT and (b) FAT.

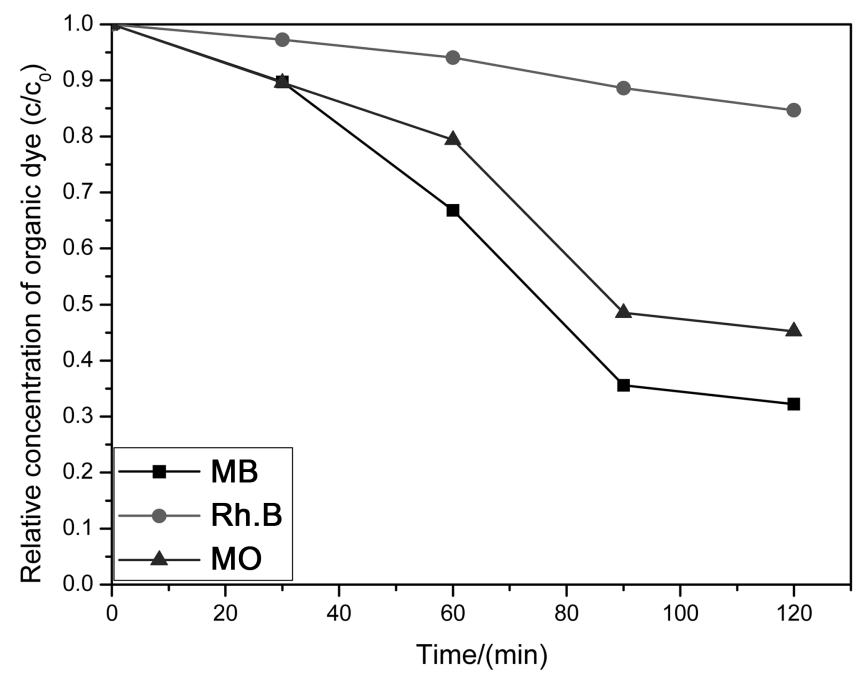

Fig. 4. Adsorption capability of $\mathrm{Fe}-\mathrm{ACF} / \mathrm{TiO}_{2}$ for different organic dyes under dark condition.

(112), (200), (211), and (204) planes of anatase. No significant diffraction peaks of rutile-phase $\mathrm{TiO}_{2}$ were detected in the XRD spectra. The phenomena mentioned above can be attributed to the two following facts that 1) thin $\mathrm{TiO}_{2}$ layers are tightly connected to the carbon fibers surfaces, and 2) the carbon surfaces that are located under the $\mathrm{TiO}_{2}$ layers can suppress the phase transformation of $\mathrm{TiO}_{2}$ from an anatase to a rutile structure at a high temperature. ${ }^{41,42)}$ According to previous studies, ${ }^{4344)}$ pure anatase nanocrystallites are very efficient photocatalysts, which is the result of their excellent photocatalytic properties. Moreover, in the curve of $\mathrm{Fe}-\mathrm{ACF} / \mathrm{TiO}_{2}$, one can clearly find the peaks of $\mathrm{Fe}$, which was further supported by observation via EDX elemental microanalysis of $\mathrm{Fe}-\mathrm{ACF} / \mathrm{TiO}_{2}$.

For the elemental analysis of non-treated $\mathrm{ACF} / \mathrm{TiO}_{2}$ and $\mathrm{Fe}-\mathrm{ACF} / \mathrm{TiO}_{2}$ composites after heat treatment, samples were analyzed by the EDX. The EDX spectra of samples are

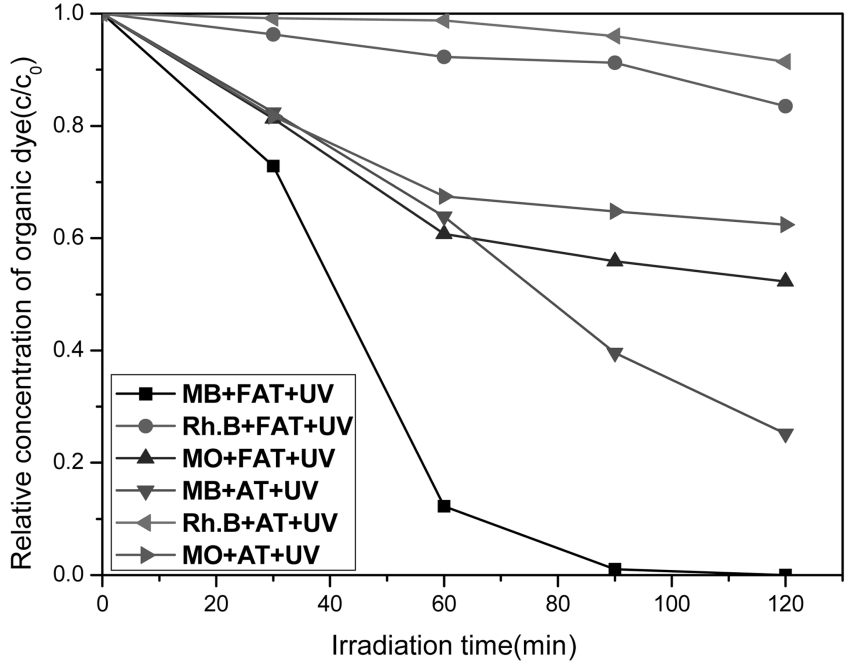

Fig. 5. Dependence of relative concentration of MB, Rh.B, and $\mathrm{MO}$ in the aqueous solution $\ln \mathrm{Abs}(\max )_{\mathrm{c}} / \mathrm{Abs}$ $(\max )_{c 0}$ on UV irradiation time for the non-treated $\mathrm{ACF} / \mathrm{TiO}_{2}$ and $\mathrm{Fe}-\mathrm{ACF} / \mathrm{TiO}_{2}$ composites.

shown in Fig. 4. The rustles of typical EDX elemental microanalysis of $\mathrm{ACF} / \mathrm{TiO}_{2}$ and $\mathrm{Fe}-\mathrm{ACF} / \mathrm{TiO}_{2}$ composites are shown in Table 3. The results show the main presence of $\mathrm{C}$, $\mathrm{O}$, and $\mathrm{Ti}$. One can also see the peaks of Fe element in the Fe-ACF/TiO ${ }_{2}$ composites.

\subsection{Degradation of organic dyes}

In order to evaluate the absorption ability of $\mathrm{Fe}-\mathrm{ACF} / \mathrm{TiO}_{2}$ composites, degradation of different dyes were run under a dark condition, which is shown in Fig. 4. From the figure, it is clear that strong adsorption ability was observed in organic dyes, which can be attributed to the high porosity of ACF. The adsorptive efficiency of ACF to dye molecules was determined by two factors: the pore diameter of ACF and the molecular size of the dye molecule. ${ }^{45)}$ The degradation of $\mathrm{MB}$ is faster than that of MO and Rh.B, which can be explained by the fact that the MB molecules were close to a strip shape, so they were easier to be adsorbed in the same direction as the pore path. The side tropism adsorption also occurred with that of $\mathrm{MO}$ and Rh.B. It was considered that the sorption of the dye is an important parameter in determining the photocatalytic degradation rate. ${ }^{46)}$ However, adsorption had little effect on the degradation of the Rh.B. This may have resulted from the molecule structure of Rh.B, which is larger than the pore diameter of ACF.

In order to evaluate the actual photocatalytic activity of the $\mathrm{ACF} / \mathrm{TiO}_{2}$ and $\mathrm{Fe}-\mathrm{ACF} / \mathrm{TiO}_{2}$ photocatalysts, a comparison of the decomposition processes of three organic dyes, namely, photolysis and photo-Fenton reaction, were carried out, and the results are shown in Fig. 5. It was found that $\mathrm{MB}$, a widely used organic color in dyeing and textile industries, can be decomposed at a higher degree than that of MO and Rh.B under UV irradiation, as shown by the curves of the photolysis. According to previous studies, ${ }^{47,48)}-\mathrm{CH}_{3}$ elimination and $\mathrm{C}-\mathrm{N}$ scission can positively occur on the $\mathrm{MB}$ 


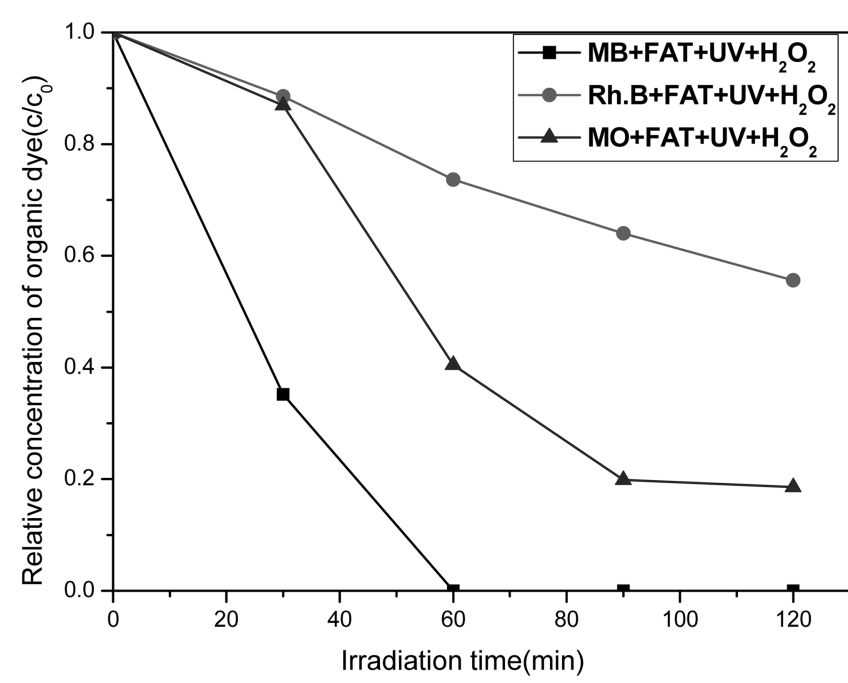

Fig. 6. Dependence of relative concentration of MB, Rh.B, and $\mathrm{MO}$ in the aqueous solution Abs $(\max )_{\mathrm{c}}{ }^{\prime}$ $\operatorname{Abs}(\max )_{c 0}$ on UV irradiation time with $\mathrm{H}_{2} \mathrm{O}_{2}$ for the $\mathrm{Fe}-\mathrm{ACF} / \mathrm{TiO}_{2}$ composites.

molecules via formation of a hydroxyl radical $\left(\mathrm{OH}^{\bullet}\right)$.

In order to degrade $\mathrm{MB}$, Rh.B, and $\mathrm{MO}$ by using $\mathrm{ACF} / \mathrm{TiO}_{2}$ and $\mathrm{Fe}-\mathrm{ACF} / \mathrm{TiO}_{2}$ composites, $\mathrm{Fe}-\mathrm{ACF} / \mathrm{TiO}_{2}$ composites were found to be more photoactive towards the three dyes solutions than $\mathrm{ACF} / \mathrm{TiO}_{2}$. It is noteworthy that the Fe modified $\mathrm{ACF}-\mathrm{TiO}_{2}$ enhanced the photocatalytic activity greatly, which was proposed to be enhanced via photo-Fenton reaction and by reducing the recombination rate of the $\mathrm{h}^{+} / \mathrm{e}^{-}$ pairs. As mentioned above the photo-Fenton reduction of $\mathrm{Fe}^{3+}$ to $\mathrm{Fe}^{2+}$ in the $\mathrm{OH}^{-}$solution under $\mathrm{UV}$ light gave rise to $\mathrm{OH}^{\bullet}$ radicals. Moreover, Fe species operated an additional electron accepting species to enhance the photocatalytic activity of $\mathrm{TiO}_{2}$, according to the following reactions:

$$
\mathrm{Fe}^{3+}+\mathrm{e}^{-} \rightarrow \mathrm{Fe}^{2+}
$$

The reactivity of the $\mathrm{Fe}^{3+}$ with the electons was photogenerated at the conduction band of $\mathrm{TiO}_{2}$ could be beneficial or detrimental factors to the oxidative processes depending on the iron species that is present in the medium. Thus, the active degradation was strongly influenced by the presence of $\mathrm{Fe}^{3+} / \mathrm{Fe}^{2+}$ in the $\mathrm{TiO}_{2}$ suspension.

\section{4. $\mathrm{H}_{2} \mathrm{O}_{2}$-assisted Fenton processes}

$\mathrm{H}_{2} \mathrm{O}_{2}$-assisted Fenton processes were also done by testing the decomposition of the above three organic dyes on the Fe$\mathrm{ACF} / \mathrm{TiO}_{2}$ composites, which is shown in Fig. 6. When comparing Fig. 5 and Fig. 6, one can see that the rates and efficiencies in the degradation of dyes were found to significantly improve in the presence of peroxides. The high decomposition rate of organic dyes when $\mathrm{H}_{2} \mathrm{O}_{2}$ was used under UV irradiation can also be observed. However, it was reported in previous studies that the amount of $\mathrm{OH}^{*}$ generated directly by the photolysis of $\mathrm{H}_{2} \mathrm{O}_{2}$ under $\mathrm{UV}$ is very small. ${ }^{49)}$ Therefore, higher photocatalytic activity can be attributed to the increase of the formation of $\mathrm{OH}$. radicals, which were caused by the oxidation of $\mathrm{Fe}^{2+}$ after addition of $\mathrm{H}_{2} \mathrm{O}_{2}$ into the reaction solutions. The reaction of $\mathrm{Fe}^{2+}$ with $\mathrm{H}_{2} \mathrm{O}_{2}$ represents a supplementary source of $\mathrm{OH}^{\text {* }}$ radicals, which resulted in the increase in the decomposition rate of the irradiated systems.

\section{Conclusion}

The results of these studies clearly indicate that organic dyes can be efficiently decomposed in the presence of photocatalysts. The results also indicate that the decomposition rate could be influenced by a number of conditions, such as the type of organic dye being used and the presence of $\mathrm{Fe}$ and $\mathrm{H}_{2} \mathrm{O}_{2}$. The rate of decomposition of MB was found to be the best among all the dyes. The rate of decomposition could be enhanced when there is a production of photo-Fenton reactions. The presence of $\mathrm{H}_{2} \mathrm{O}_{2}$ further enhanced the rate of decomposition due to the improved photo-Fenton reactions.

\section{REFERENCES}

1. U. Pagga and D. Bruan, "Behavior of Dye Stuffs in Aerobic Biodegradation Tests," Chemosphere., 15 479-84 (1986).

2. A. Bianco-Prevot, C. Baiocchi, M. C. Brussino, E. Pramauro, P. Savarino, V. Augugliaro, G. Marci, and L. Palmisano, "Photocatalytic Degradation of Acid Blue 80 in Aqueous Solutions Containing $\mathrm{TiO}_{2}$ Suspensions," Environ. Sci. Technol., 35 971-76 (2001).

3. B. Neppolian, H. C. Choi, S. Sakthivel, B. Arabindoo, and V. Murugesan, "Solar Light Induced and $\mathrm{TiO}_{2}$ Assisted Degradation of Textile Dye Reactive Blue 4," Chemosphere., 46 [8] 1173-81 (2002).

4. M. Saquib and M. Muneer, " $\mathrm{TiO}_{2}$-mediated Photocatalytic Degradation of a Triphenylmethane Dye (gentian violet), in Aqueous Suspensions," Dyes Pigments, 56 37-49 (2003).

5. B. Zielinska, J. Grzechulska, and A. W. Morawski, "Photocatalytic Decomposition of Textile Dyes on $\mathrm{TiO}_{2}$-Tytanpol A11 and $\mathrm{TiO}_{2}$-Degussa P25," J. Photochem. Photobiol. A: Chem., 157 65-70 (2003).

6. E. Vulliet, J. M. Chovelon, C. Guillard, and J. M. Herrmann, "Factors Influencing the Photocatalytic Degradation of Sulfonylurea Herbicides by $\mathrm{TiO}_{2}$ Aqueous Suspension," J. Photochem. Photobiol. A: Chem., 159 71-9 (2003).

7. P. F. Fu, Y. Luan, and X. G. Dai, "Preparation of Activated Carbon Fibers Supported $\mathrm{TiO}_{2}$ Photocatalyst and Evaluation of its Photocatalytic Reactivity," J. Mole. Catal. A: Chem., 221 81-8 (2004).

8. S. Gelover, P. Mondragon, and A. Jimenez, "Titanium Dioxide Sol-Gel Deposited Over Glass and its Application as Photocatalyst for Water Decontamination," J. Photochem. Photobiol. A: Chem., 165 241-46 (2004).

9. M. L. Chen, C. S Lim, and W. C. Oh, "Photocatalytic Effect for $\mathrm{TiO}_{2} / \mathrm{ACF}$ Composite Electrochemically Prepared with TNB Electrolyte," Carbon Letter, 8 177-83 (2007).

10. Y. N. Hou, J. H. Qu, X. Zhao, P. J. Lei, D. J. Wan, and C. P. Huang "Electro-photocatalytic Degradation of Acid Orange II Using a Novel $\mathrm{TiO}_{2} / \mathrm{ACF}$ Photoanode," Sci. of the Total 
Environ., 407 2431-39 (2009).

11. D. Q. Mo and D. Q. Ye, "Surface Study of Composite Photocatalyst Based on Plasma Modified Activated Carbon Fibers with $\mathrm{TiO}_{2}$," Surf. Coat. Technol., 203 1154-60 (2009).

12. W. C. Oh, F. J. Zhang, M. L. Chen, Y. M. Lee, and W. B. Ko, "Characterization and Relative Photonic Efficiencies of a New Fe-ACF/TiO ${ }_{2}$ Composite Photocatalysts Designed for Organic Dye Decomposition," J. Indust. Engin. Chem., 15 190-5 (2009).

13. W. C. Oh and M. L. Chen, "Electrochemical Preparation of $\mathrm{TiO}_{2} / \mathrm{ACF}$ Composites With TNB Electrolyte and Their Photocatalytic Effect," J. Ceram. Process. Res., 9 100-6 (2008).

14. N. Serpone and D. Lawless, "Spectroscopic, Photoconductivity, and Photocatalytic Studies of $\mathrm{TiO}_{2}$ Colloids: Naked and with the Lattice Doped with $\mathrm{Cr}^{3+}, \mathrm{Fe}^{3+}$, and $\mathrm{V}^{5+}$ Cations," Langmuir., 10 643-52 (1994).

15. T. Sauer, G. C. Neto, H. J. Jose, and R. F. P. M. Moreira, "Kinetics of Photocatalytic Degradation of Reactive Dyes in a $\mathrm{TiO}_{2}$ Slurry Reactor," J. Photochem. Photobiol. A: Chem., 149 147-54 (2002).

16. C. Galindo, P. Jacques, and A. Kalt, "Photochemical and Photocatalytic Degradation of an Indigoid Dye: a Case Study of Acid Blue 74 (AB74)," J. Photochem. Photobiol. A: Chem., 141 47-56 (2001).

17. F. Zhang, J. Zhao, T. Shen, H. Hidaka, E. Pelizzetti, and N. Serpone, " $\mathrm{TiO}_{2}$-assisted Photodegradation of Dye Pollutants II. Adsorption and Degradation Kinetics of Eosin in $\mathrm{TiO}_{2}$ Dispersions under Visible Light Irradiation," Appl. Catal. B: Environ., 15 147-56 (1998).

18. M. A. Hasnat, I. A. Siddiquy, and A. Nuruddin, "Comparative Photocatalytic Studies of Degradation of a Cationic and an Anionic Dye," Dyes Pigments, 66, 185-8 (2005)

19. R. W. Matthews, "Photooxidation of Organic Impurities in Water Using Thin Film of $\mathrm{TiO}_{2}$," J. Phys. Chem., 91 332833 (1987).

20. C. G. Wu, C. C. Chao, and F. T. Kuo, "Enhancement of the Photo Catalytic Performance of $\mathrm{TiO}_{2}$ Catalysts via Transition Metal Modification," Catal. Today, 97 103-12 (2004).

21. D. Dvoranova, V. Brezova, M. Mazura, and M. A. Malati, "Investigations of Metal-doped Titanium Dioxide Photocatalysts," Appl. Catal. B: Environ., 37 91-105 (2002).

22. M. A. Barakat, H. Schaeffer, G. Hayes and S. Ismat-Shah, "Photocatalytic Degradation of 2-chlorophenol by Co-doped $\mathrm{TiO}_{2}$ Nanoparticles," Appl. Catal. B: Environ., 57 23-30 (2004).

23. D. Beydoum, H. Tse, R. Amal, G. Low, and S. McEvoy, "Effect of Copper (II) on the Photocatalytic Degradation of Sucrose," J. Mol. Catal. A: Chem., 177 265-72 (2002).

24. P. A. Gay, P. Berçot, and J. Pagetti, "Electrodeposition and Characterisation of $\mathrm{Ag}-\mathrm{ZrO}_{2}$ Electroplated Coatings," Surf. Coat. Technol., 140 147-54 (2001).

25. F. Hou, W. Wang, and H. Guo, "Effect of the Dispersibility of $\mathrm{ZrO}_{2}$ Nanoparticles in Ni- $\mathrm{ZrO}_{2}$ Electroplated Nanocomposite Coatings on the Mechanical Properties of Nanocomposite Coatings," Appl. Surf. Sci., 252 3812-17 (2006).

26. Z. Zhang, C. Wang, R. Zakria, and J. Y. Ying, "Role of Particle Size in Nanocrystalline $\mathrm{TiO}_{2}$-based Photocatalysts," $J$. Phys. Chem. B., 102 10871-78 (1998).

27. W. F. Yao, H. Wang, X. H. Xu, X. F. Cheng, J. Huang, S. X.
Shang, X. N. Yang, and M. Wang, "Photocatalytic Property of Bismuth Titanate $\mathrm{Bi}_{12} \mathrm{TiO}_{20}$ Crystals," Appl. Catal. A: Gen., 243 [1] 185-90 (2003).

28. J. Feng, R. S. K. Wong, X. Hu, and P. L. Yue, "Discoloration and Mineralization of Orange II by Using $\mathrm{Fe}^{3+}$-doped $\mathrm{TiO}_{2}$ and Bentonite Clay-based Fe Nanocatalysts," Catal. Today, 98 441-46 (2004).

29. J. A. Navia, J. J. Testab, P. Djedjeianb, J. R. Padron, D. Rodriguez, and M. I. Litter, "Iron-doped Titania Powders Prepared by a Sol-Gel Method: Part II: Photocatalytic Properties,” Appl. Catal. A: Gen., 178 191-203 (1999).

30. J. Zhua, W. Zheng, B. Hea, J. Zhang, and M. Anpob, "Characterization of $\mathrm{Fe}^{-\mathrm{TiO}_{2}}$ Photocatalysts Synthesized by Hydrothermal Method and their Photocatalytic Reactivity for Photodegradation of XRG Dye Diluted in Water," $J$. Mol. Catal. A: Chem., 216 35-43 (2004).

31. I. Sirés, J. A. Garrido, R. M. Rodríguez, E. Brillas, N. Oturan, and M. A. Oturan "Catalytic Behavior of the $\mathrm{Fe}^{3+} / \mathrm{Fe}^{2+}$ System in the Electro-Fenton Degradation of the Antimicrobial Chlorophene," Appl. Catal. B: Environ., 72 382-94 (2007).

32. Y. K. Masumoto, R. Hamada, K. Yokota, S. Nishiyama, and S. Tsuruya, "Liquid-phase Oxidation of Benzene to Phenol by Vanadium Catalysts in Aqueous Solvent with High Acetic Acid Concentration," J. Mol. Catal. A., 184 215-22 (2002).

33. T. Miyahara, H. Kanzaki, R. Hamada, S. Kuroiwa, S. Nishiyama, and S. Tsuruya, "Liquid-phase Oxidation of Benzene to Phenol by $\mathrm{CuO}-\mathrm{Al}_{2} \mathrm{O}_{3}$ Catalysts Prepared by Co-precipitation Method," J. Mol. Catal. A., 176 141-50 (2001).

34. H. Kanzaki, T. Kitamura, R. Hamada, S. Nishiyama and S. Tsuruya, "Activities for Phenol Formation Using $\mathrm{Cu}$ Catalysts Supported on $\mathrm{Al}_{2} \mathrm{O}_{3}$ in the Liquid-phase Oxidation of Benzene in Aqueous Solvent with High Acetic Acid Concentration," J. Mol. Catal. A., 208 203-11 (2004).

35. M. Pera-Titus, V. Garcia-Molina, M. A. Baños, J. Giménez, and S. Espluga, "Degradation of Chlorophenols by Means of Advanced Oxidation Processes: a General Review," Appl. Catal. B: Environ., 47 219-56 (2004).

36. N. Quici, M. Morgada, R. Gettar, M. Bolte, and M. Litter, "Photocatalytic Degradation of Citric Acid under Different Conditions: $\mathrm{TiO}_{2}$ Heterogeneous Photocatalysis Against Homogeneous Photolytic Processes Promoted by Fe(III) and $\mathrm{H}_{2} \mathrm{O}_{2}$," Appl. Catal. B: Environ., 71 117-24 (2007).

37. B. Tryba, "Immobilization of $\mathrm{TiO}_{2}$ and Fe-C-TiO 2 Photocatalysts on the Cotton Material for Application in a Flow Photocatalytic Reactor for Decomposition of Phenol in Water," J. Hazar. Mat., 151 623-27 (2008).

38. Y. G. Go, F. J. Zhang, M. L. Chen, and W. C. Oh, "Fabrication of $\mathrm{Zn}$-treated $\mathrm{ACF} / \mathrm{TiO}_{2}$ Composites and Their Photocataytic Activity for Degradation of Methylene Blue," J. Mater. Res., 19 [3] 142-50 (2009).

39. F. J. Zhang, M. L. Chen, and W. C. Oh, "Synthesis and Characterization of $\mathrm{CNT} / \mathrm{TiO}_{2}$ Photoelectrocatalytic Electrodes for Methlene Blue Degradation," Kor. J. Mater. Res., 18 583-91 (2008).

40. W. D Wang, P. Serp, P. Kalck, and J. L. Faria, "Visible Light Photodegradation of Phenol on $\mathrm{MWNT}^{-\mathrm{TiO}_{2}}$ Composite Catalysts Prepared by a Modified Sol-Gel Method," J. Mole. Catal. A: Chem., 235 194-99 (2005). 
41. T. Tsumura, N. Kojitani, H. Umemura, M. Toyoda, and M. Inagaki, "Composites between Photoactive Anatase-type $\mathrm{TiO}_{2}$ and Adsorptive Carbon," Appl. Surf. Sci., 196 429-36 (2002).

42. T. Tsumura, N. Kojitani, I. Izumi, N. Iwashita, M. Toyoda, and M. Inagaki, "Carbon Coating of Anatase-type $\mathrm{TiO}_{2}$ and Photoactivity," J. Mater. Chem., 12 1391-96 (2002).

43. M. L. Chen, J. S. Bae, and W. C. Oh, "Photocatalytic Effect for the Carbon-coated $\mathrm{TiO}_{2}$ Prepared from Different Heat Treatment Temperature," Anal. Sci. \& Technol., 19 [6] 460-67 (2006).

44. M. L. Chen, J. S. Bae, and W. C. Oh, "Preparation of CarbonCoated $\mathrm{TiO}_{2}$ at Different Heat Treatment temperature and Their Photoactivity," Carbon Sci., 7 259-65 (2006).

45. S. Kasaoka, Y. Sakata, E. Tanaka and R. Naitch, "Studies on the Adsorption of Various Dyes in the Liquid Phase," Int. Chem. Eng., 29 734-42 (1989).
46. N. Barka, S. Qourzal, A. Assabbane, A. Nounah and Y. AitIchou, "Factors Influencing the Photocatalytic Degradation of Rhodamine B by $\mathrm{TiO}_{2}$-coated Non-woven Paper," J. Photochem. Photobiol. A., 195 346-51(2008).

47. Z. Q. Yu and S. C. Chuang, "The Effect of Pt on the Photocatalytic Degradation Pathway of Methylene Blue Over $\mathrm{TiO}_{2}$ under Ambient Conditions," Appl. Catal. B: Environ., 83 277-85 (2008).

48. A. Houas, H. Lachheb, M. Ksibi, E. Elaloui, C. Guillard and J.M. Herrmann, "Photocatalytic Degradation Pathway of Methylene blue in Water," Appl. Catal. B: Environ., 31 14557 (2001).

49. C. L. Hsueh, Y. H. Huang and C. Y. Chen, "Novel Activated Alumina-supported Iron Oxide-Composite as a Heterogeneous Catalyst for Photooxidative Degradation of Reactive Black 5," J. Hazard. Mater. B, 129 228-33 (2006). 